\begin{tabular}{|c|c|c|}
\hline $\begin{array}{l}\text { An International Biannual Open Access } \\
\text { Peer-Reviewed/Refereed Journal } \\
\text { JOURNAL OF GLOBAL RESOURCES } \\
\text { Published by : ISDESR, Jaipur, India }\end{array}$ & 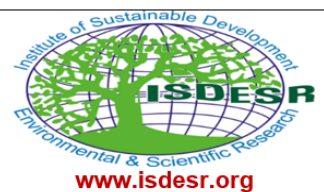 & $\begin{array}{r}\text { ISSN: 2395-3160 (Print) } \\
\text { ISSN: } 2455-2445 \text { (Online) } \\
\text { January 2022, Volume 08 (01) } \\
\text { DOI Prefix: } 10.46587 / J G R\end{array}$ \\
\hline
\end{tabular}

09

\title{
CLIMATE CHANGE AND ITS IMPACT ON THE HUMAN RIGHTS: NORTH-EAST INDIA IN CONTEXT
}

\author{
Upama Gurung \\ Research Scholar, Department of Political Science, University of North Bengal, \\ Raja Rammohunpur, Siliguri, West Bengal, India \\ Email: upamagurung@gmail.com
}

How to cite this paper:

Gurung, Upama (2022) Climate change and its impact on the human rights: North-east India in context, Journal of Global Resources, Vol. 08 (01)

DOI:

10.46587/JGR.2022.v08i01.009

Received: 11 Oct. 2021

Reviewed: 25 Oct. 2021

Revised: 01 Nov. 2021

Final Accepted: 05 Nov. 2021

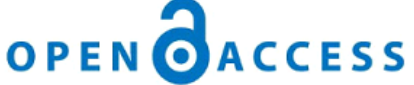

Freely available Online www.isdesr.org

\begin{abstract}
The impact of climate change upon the basic human rights of the people is emerging as a frontline research area particularly in the North East region of India- the region which is more prone to the gushing impacts of global climate change due to its geo-ecological delicateness, shared international boundaries, rugged mountain terrains and the regions' high dependency on climate sensitive livelihood such as agriculture, tea and forestry. Profound impacts of climate change in the region are being seen already in the form of rise in average temperature, slight changes in rainfall patterns, changes in the biodiversity, decrease of air quality which has ultimately threatened an array of human rights of the people in the region such as their Right to Life, Right to Food, Right to health and so on. Although Climate change has a cascading effect upon the people of the North East region of India, this area has been under-acknowledged and under-researched. Therefore, the paper purports to explore and evaluate the threats that anthropogenic climate change has imposed upon the human rights of the people of North-East India along albeit interrogating the measures that have been undertaken to address the issue and their efficacy.
\end{abstract}

Key words: Climate Change, North-East, Human Rights, Environment, Policies. 


\section{Introduction}

Climate change has been recognized as the most controversial environmental problem and the most complex challenge of the twenty first century, a debatable issue which is high on the political agenda of almost all the countries of the world today. Climate Change has been defined by the Inter-Governmental Panel on Climate Change ${ }^{1}$ as the change in the state of the climate over time, as a result of either natural variability or human activity. ${ }^{2}$ Similarly the United Nations Framework Convention on Climate Change (UNFCCC) defines Climate Change as the change of climate which is associated directly or indirectly with human action that changes the composition of the atmosphere worldwide leading to natural climate variability that can be observed over comparable time periods. ${ }^{3}$ To put it in simple words, Climate change refers to the long-term change in the earth's climate patterns primarily due to anthropogenic concentration of Greenhouse Gases into the atmosphere. Technically, the nature of the causes of climate change has been debated for years. Ample Evidences from the Royal Society, ${ }^{4}$ IPCC, have proven that climate change is anthropogenic in nature. However, opposing views have been expressed by many who believe that climate change is rather caused by natural forces and not by human interferences and even more than 1000 international scientists have dissented over anthropogenic climate change claims in Climate Depot. ${ }^{5}$ Nevertheless, one fact that everyone can agree to is that earth is warming at an alarming rate and much of this is because of human factors which in turn has led to a disastrous impact upon the enjoyment of their own basic rights.

Thus, climate change, which is the most critical challenge for humanity has, since last half century caused some disproportionate and adverse effects, particularly on the people living in vulnerable areas such as mountainous regions, small islands, polar and arid regions and upon people in vulnerable situations including indigenous people, women, children, migrants, poor people and persons with disabilities. The implications of climate change have taken manifestation in the form of food security risks, fresh water scarcity, heath related problems and displacement of larger population, thus threatening the enjoyment of internationally guaranteed human rights of the people across the planet. Thus, Climate Change poses constant threat upon the enjoyment of Human Rights as the perpetuity of the former impairs the enjoyment of the latter.

The first international agreement that took cognizance of the implications of climate change upon the human rights was the Male' Declaration on the Human Dimension of Global Climate Change ${ }^{6}$ which was adopted by the Small Island Developing States (SIDS) in November 2007 (UNEP, 2015). In the following year, the UN Human Rights Council and its Special Procedures Mechanisms issued a Resolution expressing that "climate change poses an

\footnotetext{
${ }^{1}$ The Inter-Governmental Panel on Climate Change (IPCC) was created in 1988 by the United Nations and World Meteorological Organization (WMO) with an objective to provide scientific information to all the governments which they can use to develop climate policies. It undertakes a review of all published literature relating to climate change and provides a comprehensive update on climate change.

2 See https://unfccc.int/files/press/backgrounders/application/pdf/press factsh science.pdf Accessed on 16th August, 2021 at $2100 \mathrm{hrs}$ IST.

${ }^{3}$ See https://www.ipcc.ch/sr15/chapter/glossary/ Last Accessed on August 20, 2021 at 1201 hrs. IST.

4 The Royal Society which was founded in 1660 is the oldest scientific institution in the world. It is an independent scientific academy in UK with an objective to promote the use of science for the benefit of humanity. The Society has made outstanding contribution in the field of climate change.

${ }^{5}$ Climate Depot is a project of the Committee for a Constructive Tomorrow (CFACT), a non-profit which was founded in 1985 in Washington DC to provide an alternative voice on the issues related to environment and development.

${ }^{6}$ The treaty was signed by the delegates of many Small Island Developing States in order to focus on the implications that climate change has upon the human rights of the people. The Declaration recognizes the Right to a Healthy Environment as a precondition for the enjoyment of all other Human rights.
} 
immediate and far-reaching threat to people and communities around the world"7 Thus, it is clear that anthropogenic climate change poses a grave threat upon the enjoyment of the basic human rights of the people globally and therefore, is a matter of serious concern. In this context, considering the huge population of India and excessive reliance on natural resources, our country is no exception to the impacts of anthropogenic climate change, the impact being visible also in the North-Eastern region which is considered to be highly vulnerable in terms of climate change impacts. For instance, inaccessibility of modern health care services, climate resilient agricultural system, and basic infrastructural facilities are some factors that have constrained the population of the region to withstand the effects of climate change. However, not much study has been made so far in this regard. Thus, there is an urgent need to undertake a proper and detailed study. The paper, therefore, intends to provide an overview of the impacts of climate change upon the Human Rights of the people of North-East region of the country alongside the measures that has been undertaken by both the national and regional governments so far.

\section{The Impact Of Climate Change upon Human Rights: A Concern for North-East India}

The North-East region of India comprising of 8 states (Assam, Meghalaya, Nagaland, Mizoram, Manipur, Arunachal Pradesh, Tripura and Sikkim ${ }^{8}$ ) with a total population of around 46 million is characterized by rich biodiversity, unique ethnicity, socio-cultural setup along with the world's highest rainfall region, Mawsinram in Cherrapunjee, Meghalaya. With over 70 percent of the population involved in agriculture, it is really distressing to know that the region lacks economic development and at the same time suffers from the implications of anthropogenic climate change, particularly in agriculture, forestry, health and water resource sectors and the low level of adaptability of the region adds up to this stress. The Vulnerability-Resilience Indicators Model ${ }^{9}$ has been used to assess the vulnerability and resilience of the region to climate change. According to the study, states such as Arunachal Pradesh, Sikkim, Mizoram and Meghalaya are more sensitive to the effects of climate change in terms of food security, while the water resource sensitivity of Sikkim and Arunachal Pradesh is more. Likewise, with regards to human health, all the 8 states seem to be susceptible to climate change (Singha Sutandra, 2018). ${ }^{10}$

\section{IMPACT ANALYSIS IN DIFFERENT SECTORS}

\section{Impact of Climate Change in Agriculture and Food Security}

Agriculture constitutes one of the main economic activities of the people of the North East with around 42 percent of cultivators and around 13 percent of agricultural labourers in the whole region (Jana Hiralal, Basu Debabrata, 2018). The Centre for Atmospheric Sciences at the Indian Institute of Technology, Delhi conducted a study led by Sushil Kumar Dash to assess the climatic conditions of the region. ${ }^{11}$ They projected an annual increase of about $0.64^{\circ} \mathrm{C}$ in the average

\footnotetext{
7 UNHRC (2008) Res 7/23, Human Rights and Climate Change, UN Doc A/HRC/Res/7/23

8 Prior to 2003, Sikkim was not a part of the North East region. Following the amendment of the North Eastern Council Act (1971) in December 2002, Sikkim became a part of the North East region of India as an $8^{\text {th }}$ State in the year 2003. See https://mdoner.gov.in/organisations

${ }_{9}$ Vulnerability-Resilience Indicators Model (VRIM) is used to assess the resilience and adaptive capacity balanced by the sensitivity of human and ecological system, developed by Moss, A. L. Brenkert and E. L. Malone. The model is hierarchal and divided in to 8 sectorial indicators such as food security, human health sensitivity and water resource sensitivity, through aggregation of different proxy variables using geometric averages. The indicators help to make a comparative study of different states and regions in terms of their vulnerability and resilience capacity to climate change. 10 The author used the Vulnerability Resilience Indicators Model to assess quantitatively the resilience and adaptive capacity to climate change in the entire North East region and to make a comparative study and suggest measures to improve resilience. The study found that the states of Mizoram, Sikkim and Arunachal Pradesh though more sensitive to climate change than other NE states, showed more coping-adaptive capacity. Whereas, Assam, Nagaland and Manipur showed less sensitivity and low adaptive capacity and Meghalaya and Tripura had reasonable level of adaptive capacity.

11 The Centre for Atmospheric Sciences, IIT, New Delhi conducted a study led by Prof. Sushil Kumar Dash to examine the climatic conditions of the North East region. Using the data from the Regional Climate Model Version 3
} 
surface temperature of the region by 2040 and $5.15^{\circ} \mathrm{C}$ by the end of the century. Significant amount of impact has been seen in the food grain production of many states of the North East due to an increase in average temperature and changes in rainfall patterns. For instance, Mizoram has an annual rice requirement of almost 19 lakh quintals per year but the state produces only about 4.6 quintals per annum which is likely to get worse as a result of the effects of climate change such as untimely precipitation and unfavourable weather (Government of Mizoram, 2012). Likewise, with almost 75 percent of the Himalayan glaciers retreating, many areas of the North East are suffering from water induced catastrophes such as floods and glacier lake outbursts. In 2020 around 5 million people were affected by floods in Assam alone displacing about one hundred and fifty thousand people and destroying crops worth almost 1000 crores. According to the South Assam Meteorological Subdivision, there has been a significant decrease in the rainfall pattens in the region by the rate of $11 \mathrm{~mm}$ per decade ${ }^{12}$ (Das J. Partha, 2009) which has led to drought-like situations in many districts of Meghalaya, Nagaland, Tripura and Manipur creating a serious problem of food security for the people of the respective states. Consequently, Human Rights such as the Right to food, Right to an adequate standard of living, Right to live with dignity of the people of the region has been affected due to climate change to a considerable extent.

\section{Impact of Climate Change in Health Sector}

The health status of the entire North East is extremely susceptible to the negative impacts of climate change. Shortage of food production, deterioration of air quality, exposure to different weather patterns all of which are the direct impacts of climate change have in turn led to severe health related issues such as malnutrition, increase in mortality rate, respiratory and cardiovascular diseases and other ailments. For instance, some vector-borne diseases like Malaria are more sensitive to climate change. As of 2018, almost 15.2 percent of the total cases of Malaria in the country came from the North East region. ${ }^{13}$ Changes in the level of airborne particles and pollens have also led to increased cases of respiratory problems such as Asthma and Chronic Obstructive Pulmonary Disease (COPD). The Global Burden of Disease (GBD) ${ }^{14}$ study has examined that the asthma occurrence in 2016 was highest in the states of Sikkim, Tripura and Nagaland and COPD was high in the state of Mizoram. Decrease in the agricultural yield has led to food shortages resulting in malnutrition and various deficiency diseases such as stunting and anaemia especially among the vulnerable sections. According to the data given by the Health and Family Welfare Statistics in India $(2019-20)^{15}$, the percentage of stunted children under 5 months in Meghalaya was very high of 43.8 percent in between 2015-16 (Gol, 2020). Therefore, Human Rights such as the Right to Life, Right to Education and Right to Health of the people of the North East region has been violated to a great extent as a result of climate change.

\section{Impact of Climate Change in Water Resource Sector}

As mentioned above, the impact of climate change has been so high that even the regions with very high annual rainfall have been facing drought-like situations. Moreover, with continuing

\footnotetext{
of the Abdus Salam International Centre for Theoretical Physics, Italy, they examined the temperature and rainfall variations in the region.

12 The study conducted by the members of the International Global Change Institute (IGCI), University of Waikato, New Zealand, to examine the trends and persistence in the annual precipitation of the river basins of Ganges, Brahmaputra and Meghna in each of the 16 meteorological subdivisions using the Mann Kendall Rank Statics found that decreasing level of precipitation in South Assam subdivision will have adverse impact upon the agriculture and water supply in the region.

${ }^{13}$ Available online https://nvbdcp.gov.in/ Accessed on August 19, 2021 at 2202 hrs. IST.

14 The Global Burden of Disease (GBD) study which is led by the Institute of Health Metrics and Evaluation (IHME) examines the health challenges faced by the people across 204 countries including data on 369 diseases and injuries and 87 risk factors.

${ }^{15}$ Available online at https://main.mohfw.gov.in/sites/default/files/HealthandFamilyWelfarestatisticsinlndia201920.pdf Accessed on August 19, 2021at 1700 hrs IST.
} 
retreat of the Himalayan glaciers, water flow in the glacier-fed rivers have increased causing floods that affects groundwater quality and uneven precipitation and warmer temperature eventually has led to water scarcity in the river basins of Brahmaputra. If the current warming trends continue, the average annual runoff in the Brahmaputra will decline by 14 percent. ${ }^{16}$ In Manipur out of total 4.5 lakh rural households, drinking water is accessible to only about 1.6 lakh. Similarly, many districts of Sikkim, Nagaland and Assam are under severe water stress. It has been projected that by 2030, the number of rainy days is likely to decrease by 1-10 days Gol, 2010) which means more scarcity of freshwater. This is a serious cause for concern as the anthropogenic climate change is violating the most basic Human Rights of the people of the region such as the Right to safe drinking water and sanitation, Right to health and Right to Life.

\section{Impact of Climate Change in Infrastructure and Human Settlements}

The effects of Climate change upon human settlements are being seen already in many parts of North East India in the form of migration and displacement and loss of infrastructure. Erratic and extreme weather and irregular rainfalls which has caused floods in some places and droughts in others, resulting in crop loss, health problems and many other issues have led to forced migration of the people. This is particularly true of many villages in Assam living along the banks of river Brahmaputra. Up to the month of July of this year, 22 villages were submerged and around 413.3hectare crop area had been destroyed due to floods in Assam. Furthermore, in 2020, over 1.5 lakh people were affected and more than 40 villages were submerged due to flood in the western Garo Hill region of Meghalaya. Large number of people have been rendered landless and homeless as a result of climate change and this is likely to increase in the coming years. In addition to this, huge number of schools, roads, bridges and power houses are also destroyed every year as a result of such disasters. Thus, owing to heavy crop damage, infrastructural damage and threat to millions of lives, the only plausible alternative for the people is migration. Hence, climate change has affected peoples' right to property, right to housing, right to education, right to self-determination and right to adequate standard of living.

\section{Existing Climate Change Policies and Programmes: An Evaluation}

The impact of climate change upon the Human Rights of people of the North East region is extensive. The government- both national and regional have the obligation to protect and ensure smooth enjoyment of human rights by the people and to see that the effects of climate change do not impair the fulfilment of such rights. So far, very few policies and programmes have been implemented by the government with regards to climate change adaptation and mitigation in the North East region.

1. Indian Network for Climate Change Assessment (INCCA): Launched in 2009 with the purpose of enhancing knowledge about the impacts of climate change at both national and regional levels (Gol, 2014).

2. National Bank for Agriculture and Rural Development (NABARD): has been accredited as National Implementing Entity (NIE) for India for Adaptation Fund created under the UNFCCC. THE NABARD has implemented several developmental projects which had helped to develop the adaptive capacity of the rural communities to a larger extent.

3. The National Action Plan on Climate Change (NAPCC): launched in 2008 with an objective to subsume climate change through adaptation and mitigation alongside

\footnotetext{
16 The Third Assessment Report by Working Group II of the Inter-Governmental Panel on Climate Change (IPCC) in February 2001 that examined and assessed the adaptive capability and vulnerability of both human and natural systems to climate change and the potential impact of climate change. Full report available online https://www.ipcc.ch/site/assets/uploads/2018/05/SYR TAR full report.pdf Accessed on August 14, 2021 at 1505hrs IST.
} 
guaranteeing country's development, the NAPCC has eight missions: (i) the National Solar Mission, (ii) the National Mission for Enhanced Energy Efficiency, (iii) the National Water Mission, (iv) the National Mission for Green India, (v) National Mission on Sustainable Habitat, (vi) National Mission for Sustainable Agriculture, (vii) National Mission for Sustaining the Himalayan Ecosystem, and (viii) National Mission on Strategic Knowledge for Climate Change. ${ }^{17}$

4. India's North East Climate Change Adaptation Programme (NECCAP): The project is a bilateral agreement between the Government of India and Germany which is being implemented in the states of Assam, Meghalaya, Nagaland and Sikkim to enhance the climate resilience of rural communities. This programme aims to reduce the climate change vulnerability of the target groups, thus, increasing their adaptive capacity. (DoNER, Gol, KfW Development Bank, 2010).

5. State Action Plan on Climate Change: The PM called upon all the states to make their own action plan on climate change in August 2009. Each state prepares their own framework of action to respond to the threats of climate change.

6. The National Adaptation Fund for Climate Change (NAFCC): established by the Government of India in 2015 for the purpose of assisting those States and UTs that are vulnerable to the impacts of climate change. So far, it has sanctioned 30 projects, out of which 28 are state-specific including 7 projects for North East region. Such as, Model Carbon Positive Eco-Village in Phayeng of Manipur, Addressing Climate Change Vulnerability of Water Sector at Gram Panchayat Level in Drought prone areas of Sikkim, ${ }^{18}$ and five other projects for the states of Mizoram, Assam, Arunachal Pradesh, Nagaland and Meghalaya.

However, regardless of the initiatives taken by the governments, national and regional both, it seems that the existing policies and programmes have not been adequate enough to fight against the potential implications of climate change, let alone its effect upon the human rights of the people of the region. Floods continue to cause mayhem in states like Assam and Meghalaya, the government has failed to take concrete steps in providing rehabilitation to the displaced lot or even provide enough compensation to the villagers whose crops are damaged due to floods and droughts. Water, which is an indispensable component is still in scarcity in many parts of the North East. Although extensive health programmes have been sanctioned, number of climate related diseases keep increasing causing countless deaths in the region. Until now, only a couple of programmes have been initiated by the government in the North East region specifically to deal with the impacts of climate change. The NAPCC also seems to lack budgetary resources and capacity building at the regional level. Even the state governments have failed to provide alternative livelihood opportunities to the people. Lack of transparency and accountability, inadequate emphasis upon the implementation of water policies and water security plans, undersupply of research in climate change and impact assessment, absence of coordination amongst the state governments of the region, need of public knowledge of the policies and legislations and lack of efficient and effective enforcement of climate change policies and regulations are some of the inadequacies that has led to the inefficacy of the climate change policies and legislations sanctioned by the government so far. Climate change is a worrying trend and to deal with this the central as well as the governments of the North East region should make an increasing effort to mainstream climate change policies into the sectoral programs such as health and agriculture.

\footnotetext{
${ }_{17}$ Available online at https://prsindia.org/files/budget/budget parliament/2021/DfG percent20Analysis percent20202122 percent20Environment percent20Forests percent20and percent20Climate percent20Change.pdf Last Accessed on November 1, 2021 at $1101 \mathrm{hrs}$ IST.

18 See https://www.nabard.org/content.aspx?id=585
} 


\section{Conclusion}

Climate change which has been recognized as the most critical problem of this century has been found to impede the enjoyment of our human rights extensively and there is every possibility that this threat will amplify in the absence of strong and effective regulatory measures in the coming years. Although there has been insufficient amount of research and data, there is no denying the fact that climate change continues to violate the human rights of the people of the North East to a great extent. Coupled with lack of development, this constitutes a serious problem for the people of the region and the nation collectively. Lack of sufficient data, funds and alternative measures has further aggravated the issue. It's about time that all the governments of the North East states take initiative in formulating and implementing policies and legislations and take immediate steps to ensure that climate concerns are incorporated in all the developmental plans for the region. Steps such as increasing awareness among the people and encouraging their participation; providing permanent rehabilitation arrangements for those who have been displaced should be undertaken and there should also be proper methods to assess the level of climate change and its impact. Most importantly, Human Rights should be incorporated in climate policy making. Lack of local knowledge about the implications of climate change is definitely a bottleneck in the formulation and implementation of policies. Therefore, local knowledge and experiences should be engaged in adaptation and mitigation strategies. Diligent study needs to be done at regional scale. It is time for the national and regional planners to take cognizance of the impact of climate change upon the human rights of the people of the North East region and take immediate and necessary action for its mitigation.

\section{References}

1. Balasubramanian Muniyandi, Birundha Dhulasi V. (2012). Climate Change and its Impact on India, The IUP Journal of Environmental Sciences, Vol VI, No 1 pp. 31-46.

2. Das Anup, Ghosh P. K., Choudhury B. U., Patel, D. P., Munda G. C., Ngachan S. V., Choudhury Pulakabha (2009). Climate Change in North East India: Recent Facts and EventsWorry for Agricultural Management. ICAR Research Complex for NEH Region, Umiam, Meghalaya, India pp. 32-37.

3. Das Debojyoti (2016). Changing Climate and its Impact on Assam, Northeast India, Bangdung: Journal of the Global South, DOI 10.1186/s40728-015-0028-4

4. Das J. Partha (2009). Water and Climate Induced Vulnerability in North East India: Concerns for Environmental Security and Sustainability, WATCH Research Report 1. AARANYAK. Guwahati, Assam, India.

5. DoNER, Gol, KfW Development Bank (2010). North East Climate Change Adaptation Programme (NECCAP), Project Document. Retrieved from https://mdoner.gov.in/contentimages/files/Project Document NECCAP-31052011.pdf

6. Gogoi Elizabeth (2017). India's State Action Plans on Climate Change: Towards Meaningful Action, Oxford Policy Management In Depth Series, United Kingdom.

7. Gol (2010). Climate Change and India: A 4×4 Assessment, A Sectoral and Regional Analysis for 2030s, Indian Network for Climate Change Assessment, Ministry of Environment and Forests, New Delhi, India.

8. Gol (2014). India's Progress in Combating Climate Change, Briefing paper for UNFCCC CoP 20 Lia, Peru, Ministry of Forests, Environment and Climate Change, New Delhi, India.

9. Gol (2020). Health and Family Welfare Statistics in India 2019-20, Ministry of Health and Family Welfare Statistics Division, New Delhi, India.

10. Government of Mizoram (2012). State Action Plan on Climate Change: Mizoram (2012-17), Directorate of Science and Technology, Govt. of Mizoram.

11. India State-level Disease Burden Initiative CRD Collaborators (2018). The Burden of Chronic Respiratory Diseases and their Heterogeneity Across the States of India: The Global Burden of Disease Study 1990-2016, Lancet Glob Health, Vol 6, Issue 12, pp E1363-E1374.

12. Jain K. S., Kumar Vijay, Saharia M. (2012). Analysis of Rainfall and Temperature Trends in North East India, International Journal of Climatology, Vol 33, Issue 4, pp. 968-978. 
13. Jana Hiralal, Basu Debabrata (2018). Agricultural Backwardness Analysis of North East India: A Cause of Concern for National Development, International Journal of Current Research, Vol 10, Issue 12, pp. 76825-76831. DOI: https://doi.org/10.24941/ijcr.33598.12.2018

14. Lairenjam C., Hodam S., Bandhopadhyay A., Bhadra A. (2017). Historical and Temporal Trends of Climatic Parameters in North East India, Global NEST Journal, Vol 19, No 4 pp 547-561.

15. Malone E. L. (2009). Vulnerability and Resilience in the Face of Climate Change: Current Research and Needs for Population Information, Battelle, Washington, USA.

16. Mani Muthukumara, B. Sushenjit, Chonabayashi Shun, Markandya Anil, Mosier Thomas (2018). South Asia's Hotspots- The Impact of Temperature and Precipitation Changes on Living Standards, Internal Bank for Reconstruction and Development, World Bank, Washington DC, USA.

17. Moss R.M. H., Brenkert A. L., and Malone E. L. (2001). Vulnerability to climate change: a quantitative approach. Pacific Northwest National Laboratory (PNNL-SA-33642). Prepared for the US Department of Energy, pp. 155-167.

18. Nair Malini, Gopalkrishnan Ranjith, Rao S. Ananya, Rao Sandhya, Ravindranath H. N., Sharma Nitasha, Malaviya Sumedha, Tiwari Rakesh, Sagadevan Anitha, M. Madhushree, K. Niharika, Bala Govindasamy (2011). Climate Change Vulnerability Profiles for North East India, Current Science, Vol 101, No 3 pp 384-394.

19. Priyadarshini Subhra (2013). India's North East Gets Attention from Climate Change Scientists. https://www.natureasia.com/en/nindia/article/10.1038/nindia.2013.41 Accessed on 16th August, 2021.

20. Roychoudhury Murchana (2017). Exploring the Environment and Migration Nexus in the Brahmaputra Valley, Kolkata: Mahanirban Calcutta Research Group, Kolkata, West Bengal, India.

21. S. K. Devojit, M. K. Pradumnya, Bhattacharya R. D., Chellappan Savitha, Balasubramani K., Barman Keshab, Kumar S. Nachimuthu, Dash Prasad Aditya, Prakash Anil, Nina B. Praveen (2019). Malaria in North East India: Importance and Implications in the Era of Elimination, Microorganisms, Vol 7, Issue 12, doi: $10.3390 /$ microorganisms7120673

22. Saikia U. S., Hazarika Samarendra (2020). Climate Change: A North East India Perspective, National Innovations in Climate Resilient Agriculture (NICRA), Division of Natural Resource Management, ICAR Research Complex for NEH Region, Umiam, Meghalaya, India.

23. Singha Sutandra (2018). Assessing Vulnerability and Resilience in the Face of Climate Change: A Case Study of North-East India, European Journal of Sustainable Development, Vol 7, No 3, pp. 53-64. Doi: 10.14207/ejsd.2018.v7n3p53

24. UNEP (2015). Climate Change and Human Rights, Columbia Law School in collaboration with Sabin Centre for Climate Change Law. https://wedocs.unep.org/20.500.11822/9934 